\title{
The Dynamic Mechanism of the Development of the Mobile Internet Industry
}

\author{
Zhang Yuxin \\ School of Advertising, Communication University of China, Beijing, China
}

\begin{abstract}
Through the observation of industry facts of the mobile internet industry, the article aims to explore the dynamic mechanism which affects the development of the mobile internet industry. The dynamic mechanism consists of technology, economic incentive, user's demand and policy, which form to an interactional system. The technology is the guiding force of the industry, reflecting in chasing and imitating the advanced technology overseas in China. The economic incentive reflects in the leading effect of the economic rule and the driving effect of the economic profit, and acts on the production and operation of relative enterprises. The power of user's demand reflects the power of the market. The policy reflects the management and regulation from the government, which regulate and lead the development of the industry.

Index Terms - mobile internet industry, dynamic mechanism, technology innovation, economic incentive, user's demand, industry policy
\end{abstract}

\section{Introduction}

At the end of the $20^{\text {th }}$ century, mobile telecom industry and internet industry experienced a fast development, and gradually integrated with each other, which produced the mobile internet industry. In February 1999, Japanese telecom operator NTT DoCoMo launched "i-mode" as its pioneering mobile internet service, which began the era of the international development of mobile internet industry. China Mobile launched its value added service "Monternet" in 2001 which was the symbol of the beginning of the mobile internet in China. After that, the mobile internet quickly industrialized, and stepped into its rapid development stage years ago, which made mobile internet industry a significant social phenomenon and economic phenomenon. The article bases on the facts of mobile internet industry in China, uses theories of industrial economics, management and communication, in order to analyze the dynamic mechanism of the mobile internet industry development. Before that, I need to define mobile internet which has plenty of different definitions.

\section{The Definition of the Mobile Internet}

The mobile internet is a new concept, which refers to many stakeholders. So there are a variety of definitions from different enterprises in the industry chain, different research institutes and government regulators.

The WAP Forum (1999) defined that "mobile internet is the form of data exchange through various mobile networks among different mobile terminals (www.wapforum.org)." The ZTE Corporation (1999) gave the definition based on the type of the network: the narrow sense of the mobile internet refers to users having access to internet by mobile terminals through cellular network (WLAN, GPRS, GSM, CDMA, TD-SCDMA, WCDMA, etc.); the generalized sense of the mobile internet refers to users having access to internet by mobile terminals in wireless ways, such as WLAN, BWLL, CDMA, etc [1]. Professor Song Junde (2005) gave a more specific definition based on narrow sense: the mobile internet is that mobile terminal user access to internet through cellular network in order to obtain abundant information and thousands of services in internet at anytime anywhere, it is a wireless internet system which consists of $3 \mathrm{G}, 4 \mathrm{G}$, etc[2]. The Telecom Research Institute of the Ministry of Industry and Information (2011) defined the mobile internet in generalized sense and pointed out three indispensible elements which constitute mobile internet were mobile terminal, mobile network and mobile applications( or content service)[3].

Though there are different visions of the definitions of the mobile internet, they have the similar connotations. Firstly, the mobile internet emphasizes its characteristic of "mobile", including accessing through wireless network, by using mobile terminals, which makes it totally different from the desktop internet. Secondly, the mobile internet aims to obtain all kinds of internet services, which makes it different from traditional mobile telecom. Thirdly, mobile network, mobile terminal and mobile application constitute the mobile internet system. To sum up, I define that the mobile internet is the way that users obtain abundant of content, information and services in internet through cellular networks and wireless broadband networks, by all kinds of mobile, portable terminals.

\section{The Dynamic Mechanism of the Development of the Mobile Internet Industry}

The studies referring to the development of the mobile internet mostly come from the study field of mobile telecom, which makes most of the recent studies focus on the technology evolution and the switch of the operator's operating management strategies, including developing new service, establishing new business model, etc. But these perspectives could present just a part of the industry. Base on that, I divide the mobile internet industry into two systems which are supply system and demand system. The supply system is forced by technology and different enterprises, and the demand system is forced by user's demand. In addition, the two systems are affected by the industry policy. Thus, I believe that the dynamic mechanism of the development of the mobile internet industry consists of technology innovation, economic incentive, user's demand and industry policy, which is also an interactional system.

\subsection{Technology Innovation}

Some scholars have the opinion of technological 
determinism when they discuss the issues referring to the role that technology plays in our society. They believe that the development of technology is independent from other factors, and the technology determines other social relations. I am not a supporter of the technological determinism, but I can't deny that the technology plays an essential role in the development of mobile internet industry. The technology is the guiding force.

\subsubsection{The technology innovation pushes the development of economy}

The technology innovation pushes the development of industry and economy directly. The technology is always an important approach to accelerate production, and technology itself has the power to develop new industrial pattern and economic pattern. The development of the mobile internet industry is a process that the industrial pattern changes continuously, even reforms, and gradually affects the economic pattern and economic structure.

Freeman and Perez (1986) proposed the concept named "technology-economy paradigm" to describe the phenomenon that widespread technology affects enterprises and industry through economic system. They believed that technology revolution would lead the relevant product, system or industry produces new scope based on its character firstly, and then affects nearly every other domains of the economy. The formation of the technology- economy paradigm relies on the revolution of science and technology, and industry. The view reveals the complementary relationships between technology evolution and industry development. The practice of technology revolution produces the most effective way to develop production, and will enable the industry to develop, even reform, which is a process that the new industry tradition (industrial technology, industrial structure, business mode, etc.) replaces the old industry tradition continuously[4].

The Innovation Theory points out that innovation and economy interact with each other. More specifically, at the time that the technology innovation helps enterprise gain high profit, it also brings imitation. When the imitation spreads, the innovation will subside, then the profit disappears, which means more innovations will be needed to stimulate the re-development of the economy. To sum up, the technology innovation is the base of the modern economy. In 1980s of the $20^{\text {th }}$ century, Paul Romer proposed the New Economic Growth Theory which considered the technology and knowledge as important endogenous variables of the economic development. The modern economic development happens in the transformation process that is from underdeveloped state to developed state and from shortage state to wealthy state, which bases on important technology innovations. In the new economy circumstance, the market is in the state of oversupply. The restriction of the economic growth is not the tangible resource any more, but the new demand point and growth point. In the digital economy era when information industry rises sharply, the creation of demand relies on the technology more and more. The development of technology not only reduces the cost of product and service effectively, but also creates new demand.
Thus, the technology innovation plays an irreplaceable role in the development of industry and economy because it grasps the key of the development of new economy.

\subsubsection{The technology innovation directly drives the mobile internet industry}

The technology is the guiding force of the mobile internet industry development. Without the invention and application of new technology in mobile internet field, people will not be able use internet services anytime anywhere. The appearance of mobile internet service relied on the development of mobile telecom technology that the cellular network had the ability of transmitting multimedia data. After that, the bandwidth, speed, coverage area and ability of CODEC of the cellular network improved continuously; the terminal's performance improved continuously; the languages of programming and content presentation were becoming more diversified, such as WAP, html5. So the development of mobile internet industry is unpractical without the improvement of the complex technology groups covering network, terminal and content, including mobile network technology, terminal hardware technology, terminal software system technology, terminal raw material technology, application system technology and safety control technology. Each mobile internet service used by people has the support of evolving technologies.

The technology innovation can not only create new growth point for enterprises in the industry chain, it can also satisfy and even create new demand of users, which brings new opportunities to the industry. For example, the evolution from $2 \mathrm{G}$ network to $3 \mathrm{G}$ network brings new growth points for equipment suppliers, technology suppliers, and operators in their production. The example for the creation of user's demand is the developing of the iOS which broke the limitation of user experience. The iOS brought new ways of browsing website by web language which replaced the WAP browsing experience, and it drove the development of the mobile application by greatly enriching the type and number of the client-side application, which stimulated the potential consuming demands of users.

But it should be noted that the technology generates potential industrial opportunities which can be applied in the certain social and economic environment, either it may not be applied. Lynn White said that new technology just opens a door, but it does not force people to walk into the room, which means that the industrial demands that produced by technology innovations usually don't get effect instantly, even can be unpredictable. Besides, among numerous technology innovations, exactly which one can be the dominating pattern and realizes large-scale industrialization depends on many factors, such as the maturity of the technology, the advantage of cost, the support of the government, the game among stakeholders, and the demand of users, etc.

\subsection{Economic Incentive}

The economic incentive is one of the most important motivations of the industry development, which includes two implications: the leading effect of the economic rule and the 
driving effect of the economic profit. Enterprises are the main objects that the economic factors act on.

\subsubsection{The Leading Effect of the Industrial Production Rule}

The production pattern and production rule of the mobile internet industry were affected by some certain economic laws. The economic development leads to the change of the industrial production rule, and then affects the development direction of the industry. On the one hand, as an integrated industry, the mobile internet industry is dominated by the traditional industrial production rule; on the other hand, as a burgeoning information industry, the mobile internet industry is affected by the net economy rule. The impact of the economic laws can be observed on the production and operation of different enterprises.

The traditional industrial production rule refers to the requirement that economy of scale expects to division of labor and cooperation in the competitive production pattern which is directed by profit [5]. To be specific, based on the requirement of scale production, the industry or enterprise should have the ability to conduct both specialized production and cooperative production. On the one hand, the social division makes the production more specialized inevitable. When the mobile internet industry just formed, the industry pattern was a typical vertical integration, and the industry chain was built around the operator. However, the division of labor is the only way which must be passed in the process of industrial deepening development. Any enterprise can't be competent for all the functions in the industry chain. Adam Smith classified the division of labor into three types which are division of labor in the enterprise, division of labor among enterprises, and division of labor in the industry or social. The second type of division of labor happened in the mobile internet industry was the symbol that the industry stepped into the specialized production stage. On the other hand, in order to maximize the use of resources and optimize the production efficiency, the cooperation is necessary. As for an integrated and open industry like mobile internet industry, there are a variety of different industrial resources, and different enterprises have different superior resources. Thus, enterprises need to obtain resources by cooperating with each other, and form a stable pattern for resource flow. At the mean time, the enterprises cluster might have higher efficiency in production. The division of labor and cooperation make the production pattern and the industry chain structure of the mobile internet industry has been changed all the time.

The mobile internet industry grows out of the telecom industry, internet industry and IT industry. As a typical information service industry which relies on digital technology and network technology would be affected by net economy rule. The most important character of the net economy rule is the network effect which means that the value of connecting to a network depends on the people who have already connected to the network. The Metcalfe Law indicates that the growth rate of the network value is in direct proportion to the square of the growth rate of number of users. Thus, the network effect is the economy rule that connects the supply side and the demand side. As the supplier, enterprise could integrate the value chain and different resources to obtain network effect. More and more mobile internet enterprises realize the power of the large-scale and standardization, and try to obtain direct network effect and indirect network effect by standardization, in order to catch the large-scale demand market. However, the domination of network effect will make the production standard become more and more centralized, and the completion of establishing standard among enterprises will become even more drastic.

\subsubsection{The Driving Effect of the Economic Interests}

Enterprises in the industry chain are main sharers of the industrial value and profit. Enterprises are not only unidirectional affected by economy rules, some enterprises which are dominated in the industry are competent to use the economy rules to maximize their own profit. The enterprise chasing for the profit is the essential power of the development of the mobile internet industry.

The mobile internet industry is considered as a huge potential market. The market of the network service (data flow service) and the terminal sales are huge. For example, the income of the data flow service of China Mobile is 68.4billion in 2012. The content service market has huge potential either, which includes the mobile data service operated by the operator, and the market of mobile content and mobile application operated by the internet company and the media. The Morgan Stanly assumes that the income of the mobile data service operated by three operators in China will reach 46.2 billion in 2015 .

The mobile internet industry was generated from the "Monternet", and the Monternet service aimed at exploring the new service increasing point at first. In 2000, the growth rate of the telecom service was $42.4 \%$ which is much higher than the growth rate of GDP $(9.1 \%)$. However, in 2001 , the growth rate of the telecom service plunged to $24.6 \%$, and decreased year by year after that. The reason of decreasing was that the business model of the operator highly relied on the voice service. Thus, the operator began its mobile internet service in order to seek new service increasing point. The development of $3 \mathrm{G}$ is a good example. Though the marketable application of $3 \mathrm{G}$ owed to the relevant industry policy, but the quick spread of $3 \mathrm{G}$ could not happen without the attraction of the huge profit. The three operators were eager to have the license to operate $3 \mathrm{G}$, in order to improve their income of the data flow service, and drive new $3 \mathrm{G}$ content service, such as mobile TV to create new revenue. The network equipment manufacturer had been an active promoter of $3 \mathrm{G}$. Because the network equipment manufacturer invested huge cost to research and develop 3G's infrastructure, the spread of $3 \mathrm{G}$ could help the manufacturer recover the cost quickly and then expend production. The mobile terminal manufacturer was positive to cooperate with operators, aimed to seize the opportunity of $3 \mathrm{G}$ mobile phone market which had huge potential.

In particular is that the strategies that enterprises make under the driving of economic profit could be harmful to the development of the industry. For occupying the market and recovering the cost quickly, the enterprise might have the 
monopolistic and predatory market behavior. In mobile internet industry, the operator controls the industry chain. They own the monopolistic mobile network, have abundant of users and strong market distribution, and they form the network effect by their advantages in resources. Under the network effect, the operator quickly steps into the field of content service and application service. However, the operator also builds a walled garden to protect the profit not be fragmented. The walled garden pattern restricts the development of providers of content and application, and the operator's protection behavior of its own content services limits some superior content service entering the market, which could limit the spread of the mobile internet and go against the industry development. As for the content service provider, some of them intend to seize the Free WAP market by bundled sales and compulsive subscription. The piratical content, vulgar content, even pornographic content would be harmful to the healthy development of the industry. Thus, for the aim of chasing the economic profit, enterprises should not only pay attention to the user and the demand market, they also need to be regulated by the government.

\subsection{User's Demand}

Dan Steinbock (2007) emphasizes that user's demand plays an important role in the mobile telecom industry. $\mathrm{He}$ says that the revolution of the mobile telecom has been the result of the technology innovation and the user's demand, and the speed of innovation depends on the market. In the mobile service, every innovation is pushed by the new technology and new market demand, which produces new product and service[6]. The user's demand stands for the role that "market" plays in the industry development. The principles of economics tell us that only the market demand of a certain product is existent, which means the consumers are willing to buy such a product, the production could recover the cost and make a profit. Thus, the technology innovation, service innovation, or production pattern innovation which can't be corresponding to the demand would be water without a source and a tree without roots.

Along with the appearance of the mobile internet, the way people receiving and consuming information becomes more personal, large-scale, diversified and spontaneous, which is the direction of the demand of the mobile internet service. In the period when information and knowledge have become essential strategic resources, people need much more information at anytime anywhere. The accumulation of the demand that people need obtain information they want at anytime anywhere stimulates the development of mobile internet industry. Taken earlier when the mobile internet service appeared, the user's demand of the information service that mobile internet supplied was small-scale, and the mobile internet service was only the value added service operated by the operator to improve the income structure, but not be industrialize. With the expansion of the user scale and the diversification of user's demand, a lot of internet enterprises, terminal manufacturers, media, and small entrepreneurial teams set foot in the field of the mobile internet service, which makes the service industrialized and large-scale quickly. As the consequence, the mobile internet industry expands in the production, the market is splintered, and more classified, specialized content and information services are provided to the user to content their demands. At the mean time, user's strong demand of characteristic service prompts the industry keeping innovative. As the following, the user's demand is interact with the production, which will be benefit for the industry development.

From the prospective of market economy, the forward value chain of mobile internet industry should be like the following: the user's demand forms the potential market, then the operator, the content provider, and the terminal provider which have the chance to contact with the user directly will provide services to the user, and at the mean time, they will compete for the support of the equipment provider and the technology provider in the upstream of the value chain. It is obvious that the source of the value chain of the mobile internet industry is user's demand. However, in the complex industry system, the industry value doesn't transmit following the idealist model. Some interest groups pay excessive attention to their own profit when they make strategy, and lead to the neglect of user's demand. Though technology innovation, economic peofit and industry policy all play important roles in the industry development, but the way to have half the work with double results is that the user's demand should be considered and responded.

The technology innovation which could push the industry development forms a positive feedback system with the user's demand. A valued technology innovation could satisfy a certain kind of user's demand, and the user's demand could help the technology innovation industrialized. We can assume that in the mobile internet, a series of technologies make the communication transmission channel more sufficient, the content service more diversified, the integration between the terminal and the application more fluent. Meanwhile, the user's demand could transfer these industrial resources into the certain product and service gradually. To sum up, the technology decides how industrial resources would evolve, and the demand decides which industrial resource could be productive and market-oriented.

Any operating decision made by the enterprise should under the consideration of user's demand. Purchasing the maximized profit is the internal impetus when the enterprise makes an innovation, and the market demand is the external impetus. As for a rising industry like mobile internet industry, the user had no strong demand for new technology, new product or new service at the beginning, and even didn't know what they demand. If the enterprise was rushed to snatch the market, push the service into the market coercively based on their superior resource, and considered users as their passive market objectives, the supply and demand would be malposed. By now, the market demand of mobile internet industry has been through a long cultivating process to form gradually. In this process, the enterprise which is patient to explore and cultivate user market, knows how to grasp user's demand, even create user's potential demand stands out finally. 


\subsection{Industry Policy}

The industry policy gives expression to the role that government plays in the industry development. The government regulation refers to that the government regulatory agencies which have legal status and relatively independent adopt a series of acts of the administration and supervision to the regulated ones according to certain policies and regulations[7]. To be specific, the government would increase or decrease the investment to the certain industry according to the importance of the industry, and make configurable adjustment to the industrial resources by relevant industry policies, in order to guide or constrain the action of the enterprise and the consumer.

The industry policy regulates and controls the industry development. On the one hand, the mobile internet industry is a complex industry with diversified industrial resources and participants. Especially, the monopolistic and strategic resources make it necessary for the government to give some regulations and supervisions to the industry. On the other hand, the mobile industry is in its growth stage, any policy would affect it easily. As for the industry development, the policy is a macroscopical power which would not affect the product pattern, production pattern and consumption pattern directly, but is also an essential force. In the key point of the industry development, the government actively propelling relevant industry policy would guide the direction of the industry development. The industry policy could support or restrict the technology structure, resource structure and industry chain structure of the mobile internet industry by the standard, competition, content, requirements for market access, etc.

The mobile internet industry is an integrated industry, thus there is a multi-channel management. The State Council, the Ministry of Science and Technology, the National Development and Reform Commission are in charge of the central policies; the Ministry of Industry and Information and Technology takes charge of the policies referring to telecom; and the Propaganda Department of the Central Committee of the CPC, the Ministry of Culture, the State Administration of Press, Publication, Radio, Film and Television are responsible for the regulation of content. Therefore, policies which affect the development of the mobile internet industry have three levels. The first level is the national policy, thought it isn't directly relevant to the mobile internet industry, it does affect the following substantive industry measures. The second level is the industry policy, includes the industrial competitive policy, the industrial supportive policy, the industrial scientific and technologic policy, etc. For example, the Ministry of Industry and Information and Technology issued three different 3G operating licenses to China Mobile, China Unicom and China Telecom, which began the marketable application of the $3 \mathrm{G}$ technology. However, the licenses not only have a significant impact on the construction of the mobile network, but also pull the evolution of the telecommunication system and the mobile terminals, and then accelerate the development of the content industry. The third level is the policy referring to the service and business, mainly focus on the regulation of the mobile content. For now, the field of mobile content has become more and more open, the restriction from the policy is in a decreasing trend, but the media content is still under a strict supervision. At the beginning of the industry formed, there were a lot of piratic contents and pornographic contents in the market. The emphasizing of the regulation of the content would be beneficial to the industrial environment, and made the superior content not submerged by the inferior content. The regulation from the State Administration of Press, Publication, Radio, Film and Television depends on issuing the content license to control the source and the quality of the content.

A phenomenon which we can't neglect is that the government regulatory agencies might be controlled by the industry, and become a tool for the interest groups to maximize their own profit. Such phenomenon is quite obvious in the industry which has monopolistic resource, such as telecom industry and broadcasting industry. Firstly, some of the industries have both industry attribute and public attribute which are hard to separate from each other. The government finds it is difficult to have a suitable position between the two attribute when the policy is made. Take telecom industry as an example, the telecom expert Wang Xiaoqiang (1998) proposed his opinion in his paper "The development strategy of telecom industry in China" that the telecommunication network should be public, and be constructed as a national basic information network with the cable television network, managed by the national government in order to develop its public attribute. However, the expert Fang Hongyi believed that it was the consideration based on the interest of telecom industry, which intended to restrict the cable television network stepping into the operating field of telecom by free competition[8]. Secondly, in some industries, the regulatory agency is entwined with the regulated enterprises. The association of interests makes the policy lack of neutrality. The phenomenon that the enterprise is both the athlete and the referee is not uncommon in the telecom industry. At last, the mobile internet industry is an integrated industry which involves different regulatory agencies. These regulatory agencies regulate the different fields of the industry, so there are some conflicts in striving for the dominant rights because of the blurry of the regulation bound and the protection of their own profit. Therefore, the policy issued by the regulatory agency is interfered by the interest group behind more or less. The industry policy has the delicate relationship among the technology innovation, the enterprise's profit and the user's demand.

\section{Reference}

[1] ZTE Corporation, "The white paper of the technology of mobile internet", 1999

[2] Song Junde, "Some hot issues of wireless mobile internet in 2005," Academic Journal of Beijing University of Posts and Telecommunication, No.4, 2005, pp.28-29

[3] The Telecom Research Institute of the Ministry of Industry and Information, "The white paper of mobile internet in China 2011," 2011, pp. 1

[4] Yan Xianjun, "From technology-economy paradigm to informationtechnology paradigm: the role of technology-industry revolution plays in 
the transition of technology- economy paradigm," The economic research of quantitative economics technology, No.12, 2004, pp.139-146

[5] Wang Fei, Media Integration: The Media Integration Theory in the New Digital Media Era, $1^{\text {st }}$ ed., Guangzhou: Southern Daily Press, 2007, pp12

[6] Dan Steinbock, Mobile Revolution, $1^{\text {st }}$ ed, Beijing: Electronic Industry
Press, 2007, pp21,pp80

[7] Lv Tingjie, Harangue about Telecom Industry, $1^{\text {st }}$ ed, Beijing: Beijing University of Posts and Telecommunications Press, 2005, pp.65

[8] Zhou Qiren, "The Competition between Telecom and Cable Television", $1^{\text {st }}$ ed, Shanghai: SDX Joint Publishing Company, 2001, pp1-9 